Número 1, diciembre 2012 No 01/03. ISSN: 2014-5993

\title{
Semeando e Cultivando Relações \\ Transformações nas Redes de Suporte Social de Migrantes ao longo do Tempo e do Espaço
}

\author{
Tiago Augusto da Cunha \\ Doutorando em Demografia \\ Núcleo de Estudos de População (NEPO) \\ Instituto de Filosofia e Ciências Humanas (IFCH) \\ Universidade Estadual de Campinas (UNICAMP) \\ ta_cunha@yahoo.com.br
}

\section{Resumo}

Usualmente, os estudos sobre redes sociais e o processo migratório se debruçam essencialmente sobre duas vertentes: a) o direcionamento do fluxo migratório e b) e a relevância das redes no processo de integração do migrante as áreas de destino. Desse modo, o presente estudo propõe uma inversão desta perspectiva predominante, qual seja; compreender os impactos da migração sobre a rede de suporte social dos indivíduos e famílias, tanto em termos quantitativos, como em termos qualitativos. Todavia, os câmbios na rede de suporte social não estão associados tão somente a uma única variável, neste caso, à migração. Tão fundamental quanto ela são os próprios eventos do curso de vida, tais como: a) formação de um novo domicílio, b) casamento e/ou estabilidade conjugal e c) nascimento dos filhos. Para tanto, foi realizada uma série de entrevistas qualitativas, a fim de captar e mapear a rede de suporte social do migrante ao longo de cada um desses pontos de inflexão. Ademais, há uma complementação quantitativa das primeiras análises aqui feitas a partir dos dados de uma pesquisa amostral realizada em 2007 na Região Metropolitana de Campinas com o objetivo de retratar as condições de vulnerabilidade social de seus habitantes. O principal pressuposto aqui assumido é que a migração, assim como, determinados eventos/marcadores do curso de vida de um indivíduo foram responsáveis por "abrir novas portas e oportunidades" para aqueles que a realizaram ou os vivenciaram, sendo que suas condições de vulnerabilidade social foram severamente transformadas seja pelo incremento de contatos, quanto pela diversificação dos mesmos. 
Número 1, diciembre 2012 No 01/03. ISSN: 2014-5993

\section{Introdução}

Assim como cada indivíduo possui a sua própria história de vida, o conjunto de relações sociais pessoais deles como se manifestam hoje é fruto de um processo que se desenrolou ao longo dos anos (Bidart; Lavenu, 2005, Clark; Huang, 2003) e do seu espaço de vivência (Avenarius; 2012, Magdol; Bessel; 2003) - ou seja, por onde transcorreu cada uma dessas etapas de seu curso de vida.

Nesse sentido, progressivamente e ao longo de toda uma vida novas relações sociais são construídas, enquanto que outras tantas simplesmente deixam de existir, ou ainda - mais interessantemente - ficam apenas "dormentes/latentes" (Molina et al., 2008).

Isto se dá pelo fato que o indivíduo se move, participa, ou melhor, participará e pertencerá (muitas vezes de forma involuntária, inclusive) a diferentes esferas de sociabilidade, diferentes contextos, empregos, cidades, etc., associados a particulares momentos do seu curso de vida, mas também - e não menos importante - a específicos espaços nos quais viveu e conviveu com outros.

Importante é notar que as redes sociais e, talvez, mais particularmente as redes de suporte social testemunham essas transformações ao longo do tempo e do espaço.

Dessa forma, uma das hipóteses primeiras do presente estudo é que cada novo encontro cada novo contato - tecido pelo indivíduo pode abrir uma porta, uma oportunidade, porque carrega em si novos conhecimentos, ideias, insumos, informações, ajudas, suportes, contatos, etc..

Se o contato com o outro e principalmente com o diferente de si pode estar carregado de novas oportunidades, a forma como o migrante passa a ser visto é totalmente distinta.

Ele pode ser, na verdade, um privilegiado da migração e por ter migrado, já que se vê quase que "forçado" a estabelecer novos contatos dada sua própria condição de migrante ou de outro/diferente naquele novo território.

Diferentemente do que aponta a literatura (DeAngelis, 1995), sua capacidade de mobilização ao longo do tempo pode ser maior comparativamente a do indivíduo que nunca migrou ou sequer trocou de residência. É claro, que essa capacidade de mobilização e utilização de contatos não é de forma alguma imediata, mas que - como processo que é - se desenrolou ao longo do tempo, transformando-se em importante ferramenta de obtenção e transmissão de recursos. 
Número 1, diciembre 2012 No 01/03. ISSN: 2014-5993

Por certo a diversificação da rede de suporte social de um migrante pode ter inequívocos impactos positivos em situações de adversidade, riscos e vulnerabilidades até então vivenciadas por ele. Ou seja, o migrante pode se tornar menos vulnerável socialmente (Kaztman; 2001) - e possivelmente menos vulnerável de um ponto de vista relacional (Bonet i Martí; 2006, Lozares et al.; 2011) - simplesmente pelo fato de ter migrado, haja vista que este fato acabou por diversificar - de modo voluntário ou não - sua rede social e, logo, sua rede de suporte social (Bonet i Martí; 2006, Barrera; 1980).

Para tanto o presente artigo se utiliza de uma série de entrevistas qualitativas semiestruturadas realizadas ao longo do primeiro semestre de 2012 na Região Metropolitana de Campinas com migrantes e não migrantes, a fim de incialmente retratar suas redes de suporte social, suas transformações ao longo do tempo e das consecutivas migrações que realizaram com o claro intuito de observar seus processos de composição, estruturação e, porventura, diversificação e como eles repercutiram em melhores condições de enfrentamento às adversidades.

Desse modo, o estudo está subdividido em 4 seções principais (afora esta introdução e as considerações finais).

A primeira trata a respeito dos procedimentos metodológicos aqui adotados a fim de se apreender esses câmbios e seus frutos. Dentro desta mesma seção algo será tratado com mais rigor e detalhes acerca dos indivíduos selecionados, tendo-se em vista as entrevistas qualitativas semiestruturadas realizadas.

O objetivo das duas seguintes seções é discorrer sobre as redes de suporte de alguns casos exemplares - redes de suporte de adultos jovens e idosos - e seus significados e relações com distintos momentos do curso de vida de seus atores e suas características migratórias.

Por fim, uma última seção que se esforça por compreender os "frutos" daí derivados, ou seja, os ônus ou bônus das alterações das redes de suporte desses indivíduos e famílias ao longo do tempo e do espaço.

\section{Aspectos Metodológicos da Pesquisa Quantitativa e das Entrevistas Semiestruturadas}

A fim de retratar as redes de suporte social dos migrantes e não migrantes ao longo do tempo e do espaço foram estabelecidos alguns critérios de seleção anteriores ao levantamento de campo e das entrevistas semiestruturadas que aí se deram. 


\section{GRAFO Working Papers}

Número 1, diciembre 2012 No 01/03. ISSN: 2014-5993

Tendo em vista que a ideia geral é verificar a relevância da migração na diversificação da rede de suporte social desses indivíduos, retirando-os, mesmo que indiretamente, de uma condição de vulnerabilidade social - dada as novas oportunidades associadas a essa diversificação da rede - foram selecionadas algumas áreas geográficas dentro da Região Metropolitana de Campinas caracterizadas por esta condição de vulnerabilidade [adversas ou não] e denominadas pelo projeto temático "Projeto Dinâmica Intrametropolitana e Vulnerabilidade Sociodemográfica nas Metrópoles do Interior Paulista: Campinas e Santos" como Zonas de Vulnerabilidade (ZV) (Cunha et al., 2006).

A pesquisa domiciliar realizada na Região Metropolitana de Campinas contou com cerca de 1.824 questionários domiciliares, envolvendo 5.902 pessoas. Estes questionários foram aplicados a partir de uma amostra estratificada em dois estágios utilizando para tanto as chamadas "Zonas de Vulnerabilidade", estratos socioeconômicos criados com base nos dados do Censo Demográfico de 2000 (Cunha et al.; 2006, Cunha et al; 2009). Outra importante característica da pesquisa, e que merece ser destacada, é que esta considerou apenas os setores censitários urbanos para o levantamento das informações, uma vez que sua população rural não chegava a representar mais do que $3 \%$ do total da população (Figura 1).

Figura 1 - Localização das Zonas de Vulnerabilidade - Região Metropolitana de Campinas, 2007

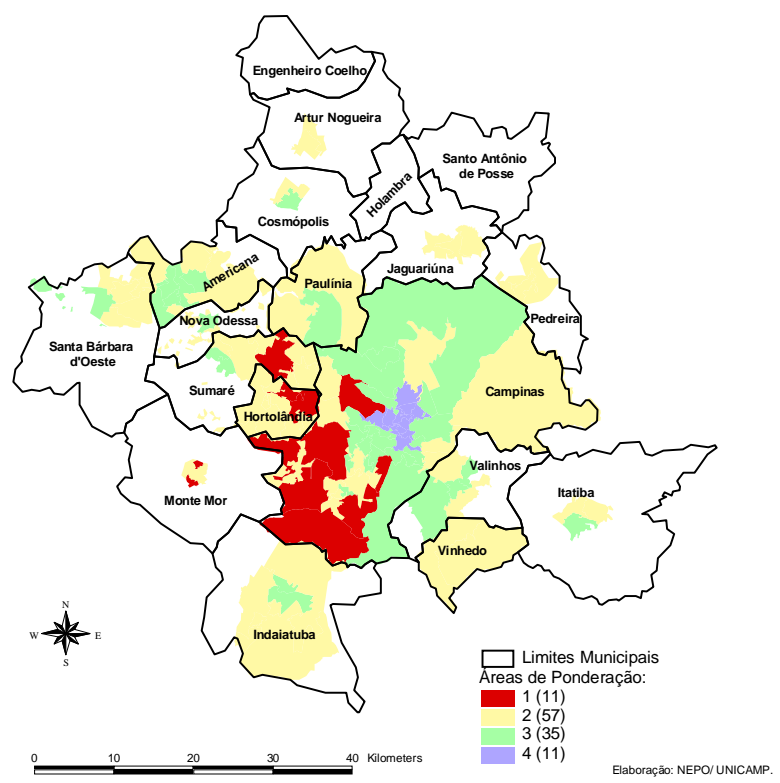

Fonte: Projeto Dinâmica Intrametropolitana e Vulnerabilidade Sociodemográfica nas Metrópoles do Interior Paulista: Campinas e Santos. NEPO/UNICAMP, 2007. 
Número 1, diciembre 2012 No 01/03. ISSN: 2014-5993

Para o levantamento de campo e, assim, para as entrevistas qualitativas e semiestruturadas, foram selecionadas apenas aqueles indivíduos residentes nas ZV1 situadas em municípios com forte crescimento do mercado de trabalho (oportunidades claras de emprego e renda, independentemente do tipo de trabalho e, consequentemente, da renda em questão) e expansão imobiliária (novas moradias). Pois, nesses casos, possivelmente novas relações sociais estão ainda sendo estabelecidas, ou seja, é quase certo que as redes de suporte estão sendo transformadas aí. Ademais, provavelmente nessas frentes de expansão urbana não só novas relações/interações sociais estão sendo tecidas como, possivelmente, novas relações/interações sociais entre indivíduos e grupos em estágios mais iniciais de seus cursos de vida - aqui associados essencialmente a formação de um novo domicílio.

Como contraponto comparativo (grupo de controle), foram também selecionados indivíduos residentes na ZV3. Já neste caso, as ZV3 encontram-se em municípios com características opostas aos escolhidos anteriormente.

Ainda acerca das Zonas de Vulnerabilidade, elas podem ser descritas da seguinte forma em termos de suas principais características:

a) Zona de Vulnerabilidade do Tipo 1 (ZV1): Zona mais periférica, tanto geograficamente, quanto socialmente. Do ponto de vista urbano, são áreas menos consolidadas, além de apresentarem infraestrutura mais deficitária. Sua população apresenta carências significativas tanto em termos econômicos, quanto educacionais; além de alto grau de desproteção social.

b) Zona de Vulnerabilidade do Tipo $\mathbf{3}$ (ZV3): Zonas urbanas mais centrais. Zona mais consolidada e, consequentemente, mais valorizada. Além disso, apresenta população de mais alta renda, além de outras particularidades - domicílios menores, unipessoais e mais envelhecidos.

Cabe também frisar que para efeitos da presente pesquisa quantitativa a unidade de análise será o domicílio, ou melhor, uma aproximação deste. A hipótese assumida é que a decisão migratória é tomada dentro da unidade domiciliar, assim, como boa parte dos contatos provedores estão conectados a ela. Dessa forma, para a análise dos dados quantitativos são tomados tanto o responsável pelo domicílio, quanto seu cônjuge, por entender que a trajetória de ambos condiciona a trajetória de quase todos os demais integrantes do domicílio. Não parece ser esse um problema pelo menos do ponto de vista amostral, haja vista que ambos correspondem a aproximadamente $52 \%$ do total de entrevistados.

Da mesma forma, as entrevistas qualitativas foram aplicadas tanto ao responsável pelo domicílio quanto a seu cônjuge. Ou seja, retrata-se dessa forma o curso de vida de um e de 
Número 1, diciembre 2012 No 01/03. ISSN: 2014-5993

outro e possíveis eventos onde eles se cruzam (casamento e nascimento de filhos, essencialmente), bem como as repercussões desses "toques" nas redes de suporte de uns e de outros.

Ademais, independentemente da Zona em questão, foram selecionados indivíduos de acordo com: a) sua modalidade migratória (migrantes externos e migrantes intrametropolitanos) e b) seu tempo de residência na região ("recentes", todos aqueles com menos de 10 anos de tempo de residência e "longa data", todos aqueles com mais de 10 anos de residência).

A seleção dos não migrantes, por sua vez, seguiu um único critério (afora a escolha da Zona de Vulnerabilidade): ter trocado de residência apenas uma vez sem que para isso tenha transpassado os limites administrativos dos municípios da região.

Foram realizadas 20 entrevistas com 10 casais, sendo que cada delas tomava cerca de 2 horas. Só algumas delas são aqui apresentadas. Contudo, as que são aqui discutidas representam boa parte das demais. Foram recolhidas algumas informações básicas a respeito do ego/entrevistado para cada uma de suas etapas migratórias ou eventos marcantes de seu curso de vida, tais como: idade, sexo, estado civil e posição/cargo de trabalho, presença ou não de filhos e se já são adultos ou não.

Ademais, foi utilizada a perspectiva de mapeamento de redes sociais egocentradas por meio do software computacional EgoNet. Já o gerador de nomes utilizado se embasava na metodologia de captação intitulada "ASSIS" de Barrera (1980).

Há um desdobramento imediato neste tipo de escolha. O que está sendo aqui mapeado e ilustrado não é necessariamente a rede social pessoal desses migrantes, mas sim sua rede de suporte social. É dizer, os contatos que, quando mobilizados, fornecem algum tipo de ajuda, suporte, recursos e informações de acordo com 6 necessidades sociais básicas (Barrera, 1980).

Além disso, também foram recolhidos dados sobre seus contatos/alteres. Dados básicos, como: nome, sexo e idade (categórica e não idade simples). Mas também dados que versam sobre a esfera de sociabilidade da qual faz parte, como por exemplo: a) parentesco (consanguinidade ou aliança), amizade (originária do emprego, dos estudos ou outras clubes, igrejas, associações de bairro, amigos de amigos, etc.) ou, por fim, vizinhança.

Por fim, ao menos tendo-se em vista o mapeamento da rede de suporte social, o entrevistado [ego] foi interrogado a respeito de cada uma das relações que porventura poderiam ou não existir entre os contatos [alteres] de sua rede. Nesse sentido, foi captada também a possível fluência de recursos interiormente à rede. 


\section{GRAFO Working Papers}

Número 1, diciembre 2012 No 01/03. ISSN: 2014-5993

Desse modo, os 4 grupos de entrevistados são: a) não migrantes que acabaram de se casar (sem filhos ou com filhos muito pequenos), b) não migrantes cujos filhos já são adultos, c) migrantes que acabaram de se casar e recém aportados (idem; sem filhos ou com filhos muito pequenos) e d) migrantes cujos filhos já são adultos e com diversas etapas migratórias internas a RMC.

\section{O horizonte pela frente}

Segundo Magdol e Bessel (2003):

"[...] exchange theory implies that more trust should be present between partners who have known each other long enough to accumulate a history of past reciprocal acts. Partners who have not known each other for very long may have more fragile exchange relations because the assumption of future reciprocity is less certain, implying less exchange among newer relationships."

(Magdol; Bessel; 2003, p. 151 - o grifo é meu)

Assim, partindo do afirmado pelas autoras, possivelmente há diferenças nas redes de suporte social de jovens e adultos. É de se pressupor que o mesmo se dê entre as redes de migrantes recentes e longa data.

Um dos casos mais interessantes é o de Franco. Franco - nome fictício dado ao entrevistado - é um adulto de aproximadamente 30 anos, nascido e criado na própria região e que hoje trabalha como profissional liberal. No momento da pesquisa acabara de se casar e compor um novo domicílio com sua esposa, Clara (também nome fictício), no próprio município onde residem seus [de ambos] familiares mais próximos. Não podem ser considerados vulneráveis dado algumas de suas características (baixo grau de dependência domiciliar, alta escolaridade, renda, ocupação e trabalho, etc.), mas, atualmente, vivem uma ZV1, o motivo dado por ambos é que os valores de casas e aluguéis em outras regiões da cidade inviabilizam morar aí. 


\section{GRAFO Working Papers}

Número 1, diciembre 2012 No 01/03. ISSN: 2014-5993

Diagrama 1 - Rede de Suporte Social - Jovem Adulto, Natural, Empregado e Casado - Responsável por Domicílio Urbano, Entrevistas Qualitativas, Região Metropolitana de Campinas, 2012

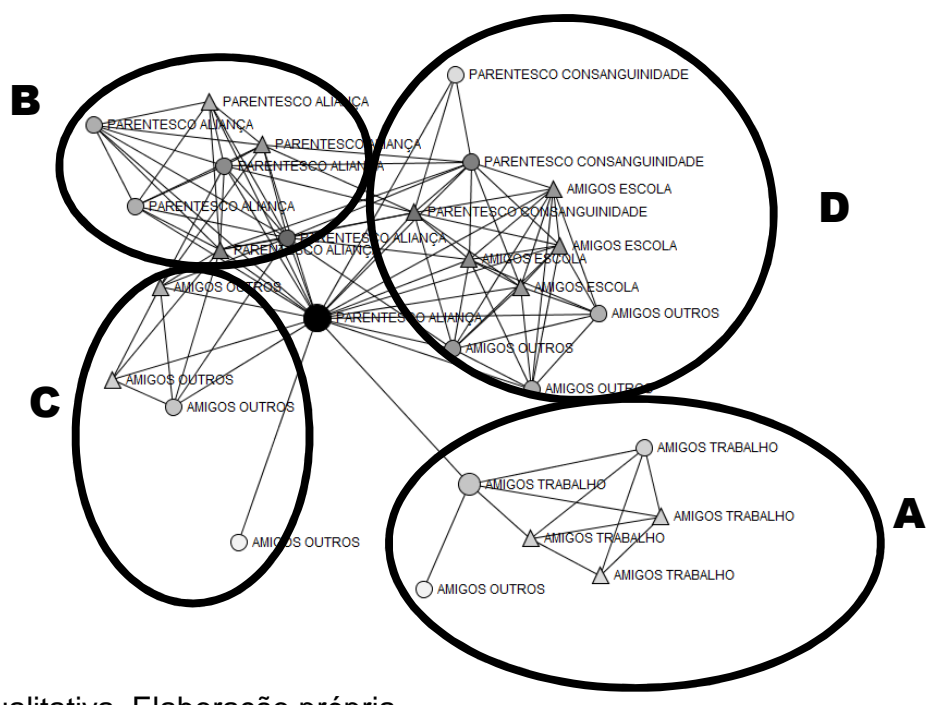

Fonte: Pesquisa Qualitativa. Elaboração própria.

Nós - ou atores - representados por triângulos se referem a indivíduos do sexo masculino. Círculos, a mulheres. O tamanho de cada nó demonstra seu grau de intermediação, ou seja, sua capacidade de vinculação entre distintos grupos ou esferas de sociabilidade do entrevistado. Enquanto que sua gradação se cores (quanto mais escuro mais central), seu grau de centralidade. Ou seja, a quantidade de relações/interações sociais que determinado ator mantém com outros nós da rede de suporte social do entrevistado.

Hoje, quem ocupa um papel central em sua rede de suporte social é sua própria esposa, Clara (círculo mais escuro no centro do diagrama). Uma boa parte das relações estabelecidas por Franco são derivadas do fato de ter conhecido e ter se casado com ela. Isso garantiu que um novo conjunto de relevantes contatos fosse incorporado a sua rede de suporte - boa parte deles familiares e/ou amigos e conhecidos de Clara (Diagrama 1).

Há, dessa forma, ao menos 4 esferas de sociabilidade que compõem a rede social de Franco tal qual hoje se encontra: a) seus amigos do trabalho, b) seus antigos amigos de escola e faculdade (e seus cônjuges), c) os amigos - e, agora, também seus - de sua esposa e d) o grande conjunto familiar formado por seus parentes.

Também é fundamental descrever a composição geral de sua rede de suporte através da participação em relação ao total de cada um dos grupos presentes na imagem acima. Assim, $10 \%$ dela era composta por familiares consanguíneos, $28 \%$ por parentes de aliança (cunhados, sogro, sogra, mas também cônjuges de seus próprios parentes consanguíneos), 


\section{GRAFO Working Papers}

Número 1, diciembre 2012 No 01/03. ISSN: 2014-5993

$14 \%$ por antigos amigos de escola e faculdade, $17 \%$ por amigos do trabalho, $28 \%$ por outros amigos (que engloba os cônjuges ou namorado(a)s deles) e, por fim, um dado muito interessante, $0 \%$ de vizinhos.

Há dois processos concomitantes que podem explicar os "por quês" pelos quais a participação de vizinhos em sua rede de suporte simplesmente inexiste.

O primeiro deles foi o curto período de residência no novo domicílio. Provavelmente neste caso não houve tempo suficiente para que relações com vizinhos figurassem como importantes relações provedoras.

O outro possível motivo que pode estar associado a pouca mobilização deles é simplesmente o fato de que boa parte de sua rede social ser composta por parentes e amigos que, mesmo havendo certa distância física entre os pares, não se encontram tão dispersos assim no território, ou seja, há certa proximidade física entre eles que garante sua mobilização em reais situações de necessidade (Hedman; 2012).

Contudo, a fim de se aquilatar a importância do casamento na composição da rede de suporte social de Franco é preciso comparar. Neste caso, compará-la com sua rede précasamento (Diagrama 2).

Diagrama 2 - Rede de Suporte Social - Jovem Adulto, Natural, Empregado e Casado - Responsável por Domicílio Urbano, Entrevistas Qualitativas, Região Metropolitana de Campinas, 2012

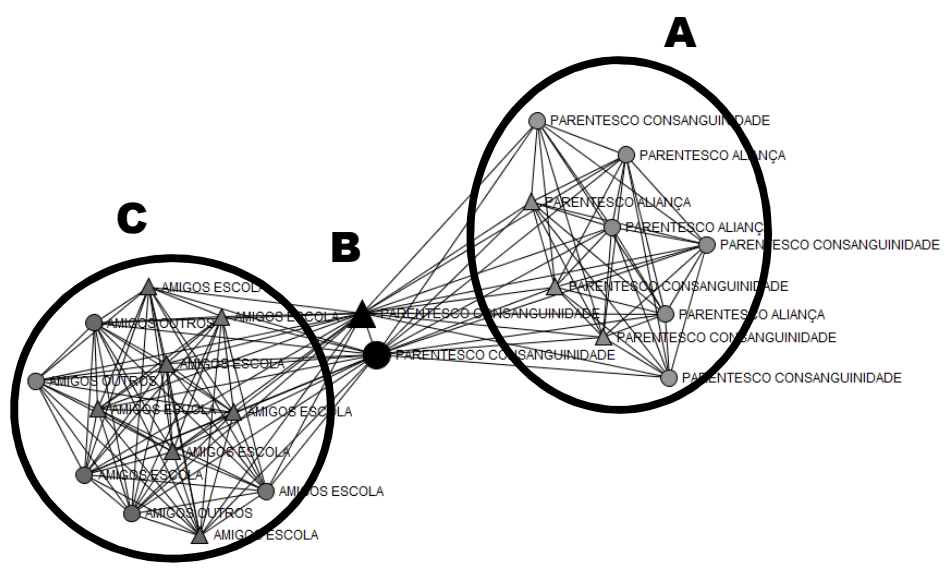

Fonte: Pesquisa Qualitativa. Elaboração própria. 


\section{GRAFO Working Papers}

Número 1, diciembre 2012 No 01/03. ISSN: 2014-5993

Quando havia acabado de finalizar seu curso profissionalizante, a imensa maioria da ajuda era proveniente de seus próprios pais. Eles mediavam, inclusive, boa parte de seus contatos, conhecendo-os e também se relacionando com eles (grupo B). Na verdade, é notável o fato que sua rede de suporte restringia-se aos parentes (grupo C), aos amigos (grupo A) e a seus pais sem nenhuma interação entre os dois primeiros grupos. Ou seja, uma rede de suporte compartimentada e que leva a crer que pouca (para não dizer nenhuma) informação corria entre grupos distintos a não ser que antes ela passasse por seus pais.

Novamente, não há participação de vizinhos. Isso, contudo, não quer dizer que não houvesse qualquer tipo de interação com eles, ou que ela nunca tenha ocorrido, mas que eles não figuravam então como os grandes provedores de ajudas nos moldes como a pesquisa foi estruturada.

O casamento, portanto, deslocou o centro de apoio da rede em uma outra direção, retirando os parentes consanguíneos (pais) de seu foco e passando-o a sua companheira; que ademais - por seu intermédio -foi responsável por diversificá-la, agregando novos contatos a mesma. Tanto assim o é que o número de contatos em uma rede era 23 e na atual, 28.

Clara, sua esposa, é também um caso interessante. Assim como Franco, ela tem aproximadamente 30 anos, está finalizando seu curso de graduação e atualmente trabalha em uma indústria da região. Contudo, diferentemente de Franco, é migrante com diversas etapas migratórias internas a RMC.

Assim como para Franco, o casamento the abriu novas portas e o acesso a novas fontes de ajuda estabelecidas, atualmente, com seus parentes e seus amigos (grupo B) (Diagrama 3). 
Número 1, diciembre 2012 No 01/03. ISSN: 2014-5993

Diagrama 3 - Rede de Suporte Social - Jovem Adulta, Migrante Intrametropolitana, Empregada e Casada - Cônjuge de Domicílio Urbano, Entrevistas Qualitativas, Região Metropolitana de Campinas, 2012

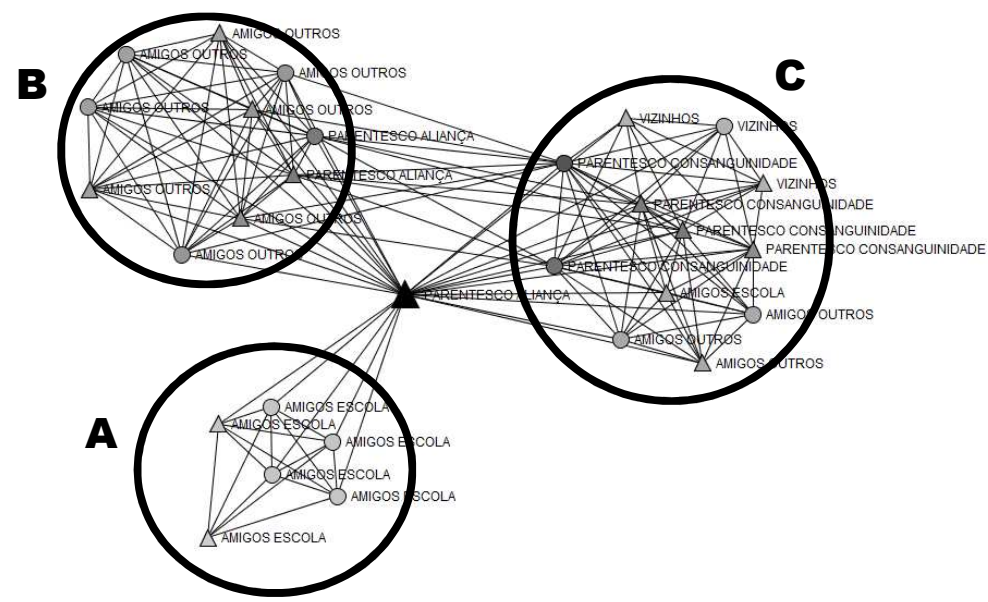

Fonte: Pesquisa Qualitativa. Elaboração própria.

Vale a pena repassar a composição de sua rede; e ela é a seguinte: 17\% por parentes consanguíneos, $10 \%$ por parentes de aliança, $24 \%$ por amigos de escola, $0 \%$ por amigos do trabalho, $37 \%$ por outros amigos e, finalmente, $10 \%$ por vizinhos.

Todavia, diferentemente do que ocorre com Franco, a mobilização dos parentes por parte de Clara é significativamente menor (27\%, enquanto que para Franco $38 \%$ ). Se a participação dos parentes é menor, outras fontes estão, portanto, assumindo seu papel ou espaço. E, de fato, é isso o que ocorre; $61 \%$ do suporte social é proveniente de amigos e $10 \%$ dos vizinhos, cifras essas notáveis - principalmente se comparadas as de Franco. Ou seja, um montante considerável (71\%) dos recursos, ajudas e suportes (inclusive materiais) é oriundo dos ditos "laços fracos" (categorias: amigos, colegas, vizinhos, etc.) e não necessariamente dos laços fortes, como sugere grande parte da literatura acerca de migração e redes (Viry, 2012). Explicado de uma outra forma, boa parte dos contatos provedores de ajuda, recursos e suportes de Clara - ou seja, dos seus ditos "laços fortes" - é composta basicamente por "laços fracos".

Tais dados são condizentes com o estudo de Jariego e Holgado (2005). Segundo os autores a própria modalidade migratória é um elemento tão ou mais importante do que estágios do curso de vida, ou ainda, do tempo de residência no processo de diversificação dos contatos de uma rede social. Ou seja, migrantes que se moviam internamente à região possuíam redes sociais mais dispersas no território do que aqueles que não se moviam e que essa 


\section{GRAFO Working Papers}

Número 1, diciembre 2012 No 01/03. ISSN: 2014-5993

dispersão geográfica produzia frutos tão diferentes entre si, quanto são as demandas por ajudas, suportes, recursos, etc..

Uma primeira hipótese é a de que os migrantes, por sua própria condição e experiência migratória pregressa possuem redes de suporte mais dispersas espacialmente e ao menos mais diversificadas. Se tomarmos as relações com vizinhos e amigos e a fluência de informações mais instrumentais (informações a respeito de oportunidades de emprego, por exemplo) como indicadores da heterogeneidade da rede parece que - assim como se passa com Clara - de fato as redes sociais de migrantes são mais diversificadas do que as dos não migrantes, portanto, mais aptas a retirá-los de uma situação de vulnerabilidade social ao menos se consideradas as vinculações do tipo "linking/bridiging" (Lozares et al., 2011).

Isso não quer necessariamente dizer que a família (vinculações que garantiriam mais coesão da rede de suporte social) deixe de ser fundamental para a mobilização de recursos e sua consequente retransmissão, mas que a rede de suporte social de Clara é significativamente mais heterogênea que a de Franco. $E$, que isso se deve a algum fator ou elemento específico que os difere. Afora a diferença de sexos (mas que também carrega em si uma diferença não trivial de gênero) e a inserção/ocupação no mercado de trabalho de ambos, a migração pode ter sido um importante mecanismo processual de diversificação da rede de suporte social de Clara (Averinarius, 2009) (Diagrama 4, Diagrama 5).

Diagrama 4 - Rede de Suporte Social - Jovem Adulta, Migrante Intrametropolitana, Empregada e Solteira - Cônjuge de Domicílio Urbano, Entrevistas Qualitativas, Região Metropolitana de Campinas, 2012

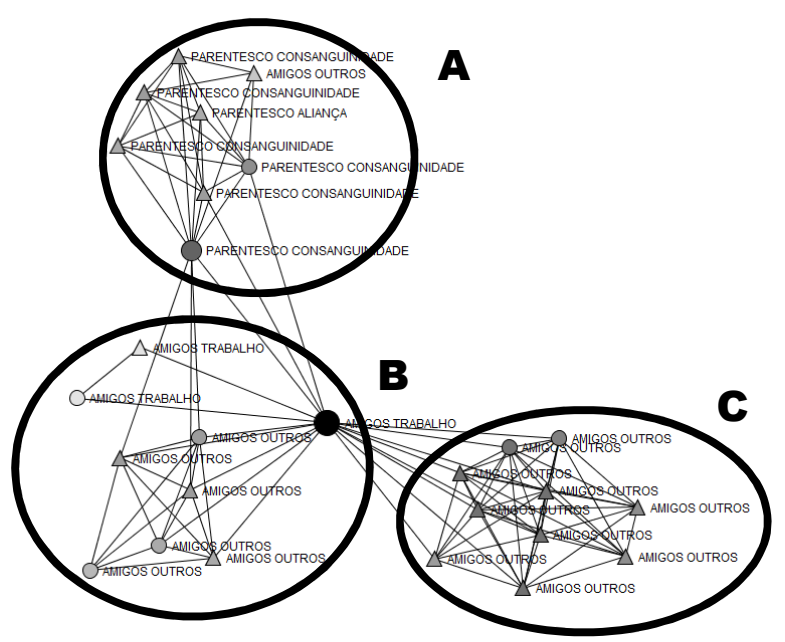

Fonte: Pesquisa Qualitativa. Elaboração própria. 


\section{GRAFO Working Papers}

Número 1, diciembre 2012 No 01/03. ISSN: 2014-5993

Diagrama 5 - Rede de Suporte Social - Jovem Adulta, Migrante Intrametropolitana, Empregada e Casada - Cônjuge de Domicílio Urbano, Entrevistas Qualitativas, Região Metropolitana de Campinas, 2012

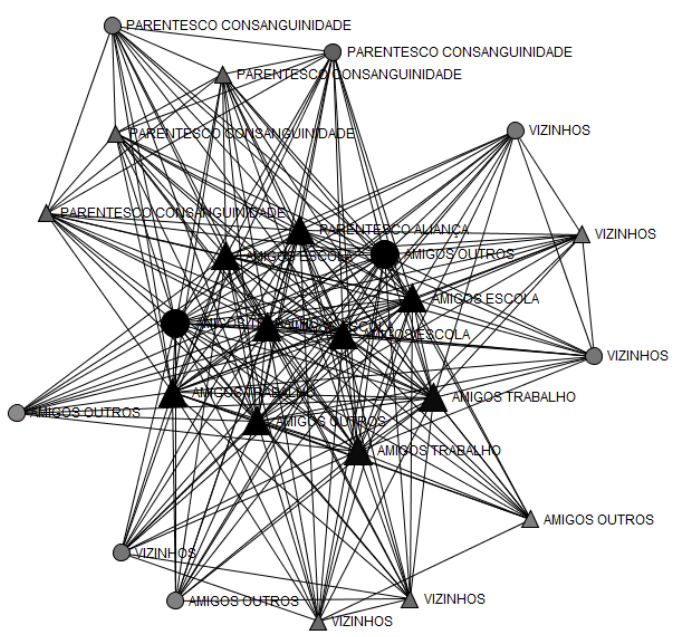

Fonte: Pesquisa Qualitativa. Elaboração própria.

Houve, portanto, - pelo menos no caso de Clara - um período de experimentação - de tentativas e erros - associada ao seu estado civil, sua idade e as consecutivas migrações entre municípios internos a RMC que realizou (foram 3) no período de pouco menos de 10 anos, bem como a consequente distância física de sua família que cada uma dessas migrações acarretou, que fez com que Clara estabelecesse novos contatos por onde passasse. É claro, essa sociabilidade também está associada a aspectos e atributos individuais, para não dizer quase que psicológicos, de Clara (sua maior sociabilidade). Todavia, parece que a migração abriu algumas portas ou, ao menos, possibilitou com que Clara se defrontasse com elas - fato que poderia simplesmente não ocorrer se ela [e sua família] tivessem permanecido "imóveis".

Muitos desses contatos da fase de "experimentação" foram carregados ao longo do tempo, perdurando em sua rede de suporte independentemente de onde ela estivesse residindo. Mas também é verdade, que boa parte dos contatos deixou de existir, ou melhor, entrou em um estado latente - quase de "hibernação" (ou seja, ainda se mantêm, contudo, não mais figuram como os grandes provedores de ajudas). Isto se deve a diversos fatores como discutido por Bidart e Lavenu (2005), mas quase sempre associados as transformações das esferas de sociabilidade desses indivíduos.

Em suma, certa distância física dos laços fortes e mais fortemente a migração fazem com que ocorra um processo de diversificação da rede de suporte social dos indivíduos com 


\section{GRAFO Working Papers}

Número 1, diciembre 2012 No 01/03. ISSN: 2014-5993

todos os ônus daí decorrentes, mas também com todos os bônus; vide o caso de Clara (novas oportunidades de emprego), daí decorrentes.

\section{Quando muito já foi construído}

Justo e Cândida têm atualmente mais de 65 anos de idade. Ambos são aposentados e têm um filho beirando os 35 anos (casado e que não mora com eles, mas reside no mesmo município). São também naturais da região, nunca tendo se mudado do atual município de residência, convivendo por muitos anos na mesma casa dos pais do Sr. Justo. Assim como Franco e Clara vivem hoje em uma ZV1 com uma diferença, sempre residiram na mesma ZV1 - ou seja, não houve mobilidade residencial ascendente, mas houve sim uma espécie de mobilidade social ascendente, dado que ao longo da vida acumularam algumas riquezas.

Assim como o que se sucedeu com a rede de Franco, as redes de suporte do Sr. Justo e da Sra. Cândida não são demasiado amplas, mas sim coesas (voltadas para si mesmas) e com majoritária participação de parentes e familiares, com um claro momento de inflexão: o casamento (Diagrama 6, Diagrama 7, Diagrama 8 e Diagrama 9).

Diagrama 6 - Rede de Suporte Social (Sr. Justo) - Idoso, Não Migrante, Aposentado e Casado Cônjuge de Domicílio Urbano, Entrevistas Qualitativas, Região Metropolitana de Campinas, 2012

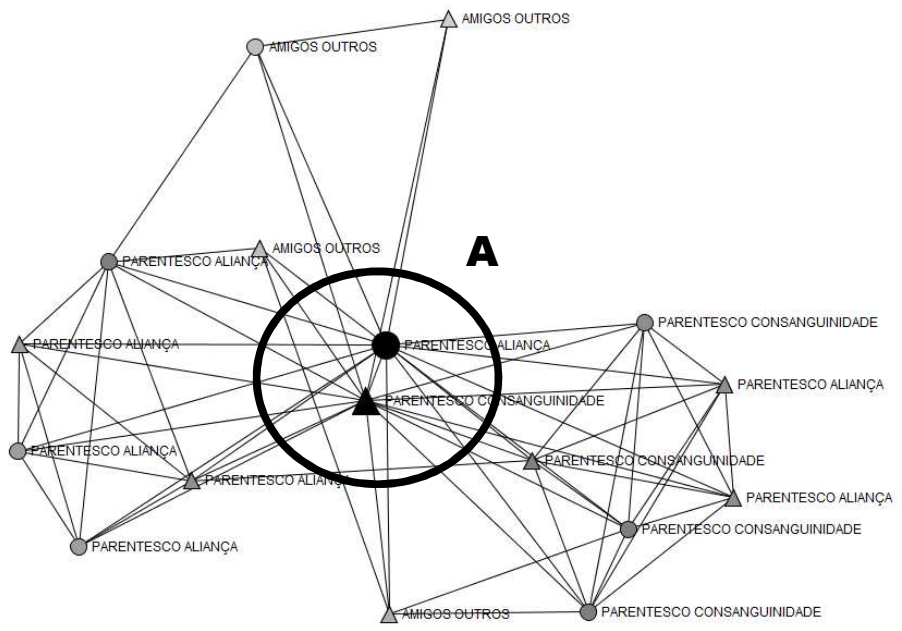

Fonte: Pesquisa Qualitativa. Elaboração própria. 


\section{GRAFO Working Papers}

Número 1, diciembre 2012 No 01/03. ISSN: 2014-5993

Diagrama 7 - Rede de Suporte Social (Sr. Justo) - Jovem Adulto, Não Migrante, Empregado e Solteiro - Cônjuge de Domicílio Urbano, Entrevistas Qualitativas, Região Metropolitana de Campinas, 2012

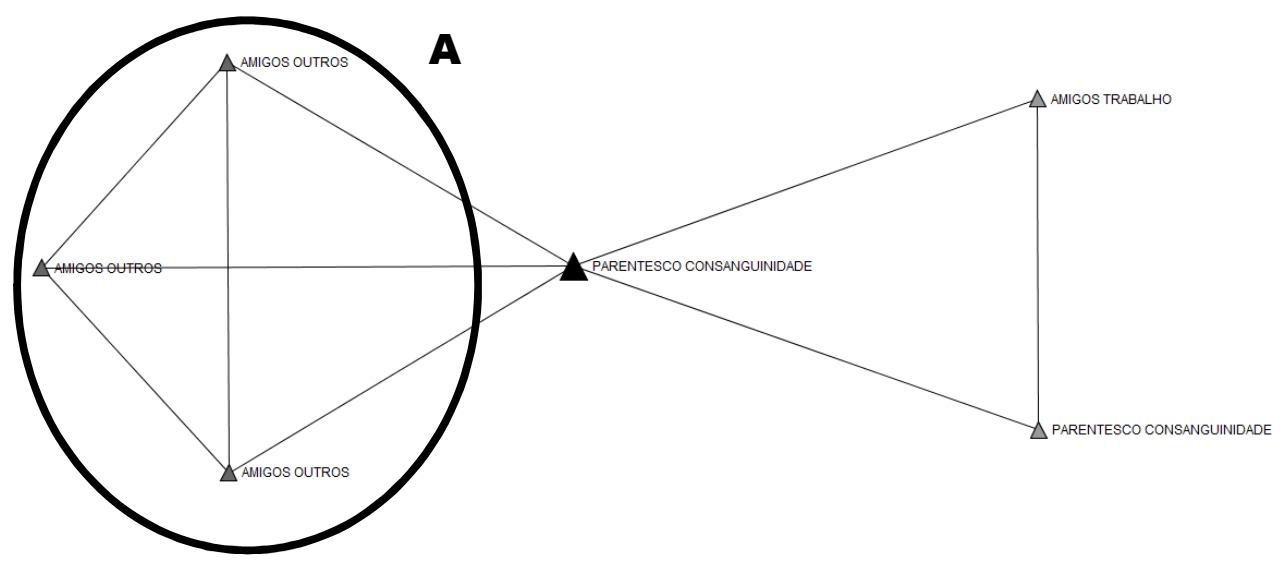

Fonte: Pesquisa Qualitativa. Elaboração própria.

Diagrama 8 - Rede de Suporte Social (Sra. Cândida) - Idosa, Não Migrante, Aposentada e Casada Responsável por Domicílio Urbano, Entrevistas Qualitativas, Região Metropolitana de Campinas, 2012

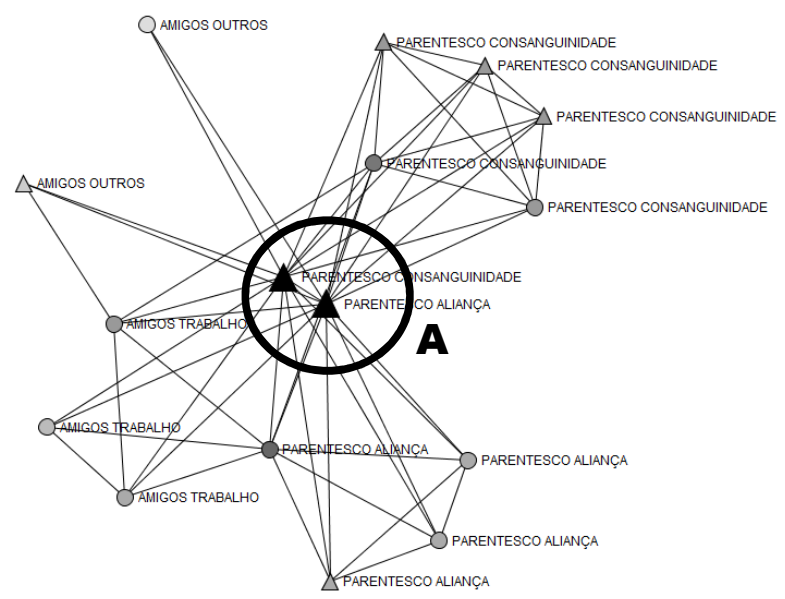

Fonte: Pesquisa Qualitativa. Elaboração própria. 
Número 1, diciembre 2012 No 01/03. ISSN: 2014-5993

Diagrama 9 - Rede de Suporte Social (Sra. Cândida) - Jovem Adulta, Não Migrante, Professora e Solteira - Responsável por Domicílio Urbano, Entrevistas Qualitativas, Região Metropolitana de Campinas, 2012

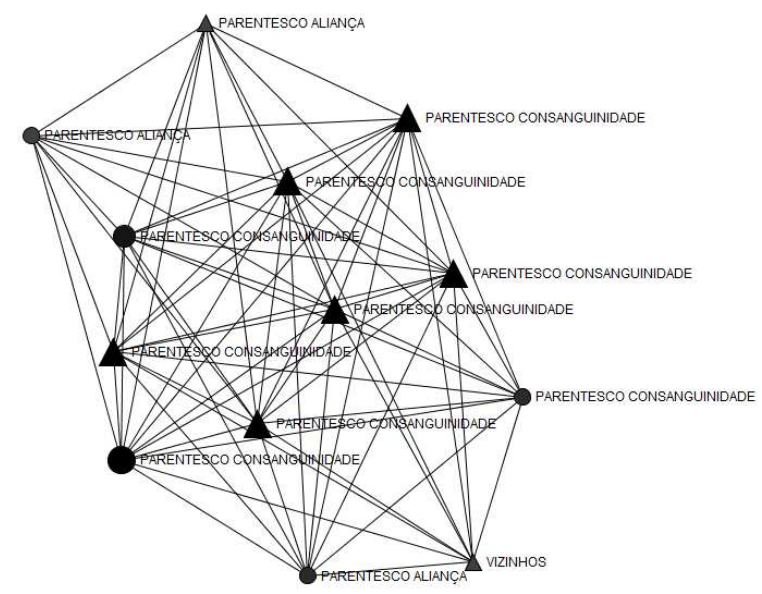

Fonte: Pesquisa Qualitativa. Elaboração própria.

O incremento de contatos é marcante no caso do Sr. Justo. Afinal, ele passa de uma rede com 6 contatos quando solteiro a uma com 17 atualmente.

O que dizer então da diversificação dos mesmos. Quando jovem geralmente obtinha algum tipo de recurso (e somente lúdico, neste caso) de apenas três amigos (grupo A - Diagrama 7); o restante era proveniente de seu próprio pai ou de um tio mais próximo. Contudo, com o passar do tempo, o número de contatos se incrementa consideravelmente com a incorporação de parentes e alguns novos casais de amigos conhecidos de sua esposa.

Uma outra peça chave para se compreender tal processo de aquisição de contatos é o seu próprio filho, através de contatos sociais estabelecidos com outros pais e amigos do filho.

O panorama é mais ou menos similar para sua esposa, Sra. Cândida. Afora o fato de ela partir de uma rede de suporte um pouco mais ampla que a do seu esposo.

Parece, portanto, que a rede dos naturais está muito alicerçada na ajuda proveniente de parentes e, portanto, recalcada nesses contatos. Ou seja, atestam que suas redes são mais homogêneas, coesas e, logo, pautadas por processos de homofilia.

Todavia, o começo da rede de suporte de um migrante não é muito distinto da rede de um não migrante, essencialmente pela relevância dos laços fortes em momentos iniciais de emancipação, mas também por aspectos de localismo destes mesmos laços fortes nos seus antigos locais de origem (Diagrama 10). 


\section{GRAFO Working Papers}

Número 1, diciembre 2012 No 01/03. ISSN: 2014-5993

Sr. Inocêncio se enquadra, atualmente, nas mesmas categorias descritivas do Sr. Justo. É aposentado, casado, com filhos. Todavia, o que os difere é sua condição de migrante (de longa data - mais de dez anos na região) e, particularmente, intrametropolitano. Ademais, o Sr. Inocêncio é ligeiramente mais jovem que o Sr. Justo - 5 anos a menos. E, reside hoje em uma ZV3 (tendo residido anteriormente em ZV1 e ZV2).

Diagrama 10 - Rede de Suporte Social (Sr. Inocêncio) - Idoso, Migrante Intrametropolitano, Aposentado e Casado - Origem - Responsável por Domicílio Urbano, Entrevistas Qualitativas, Região Metropolitana de Campinas, 2012

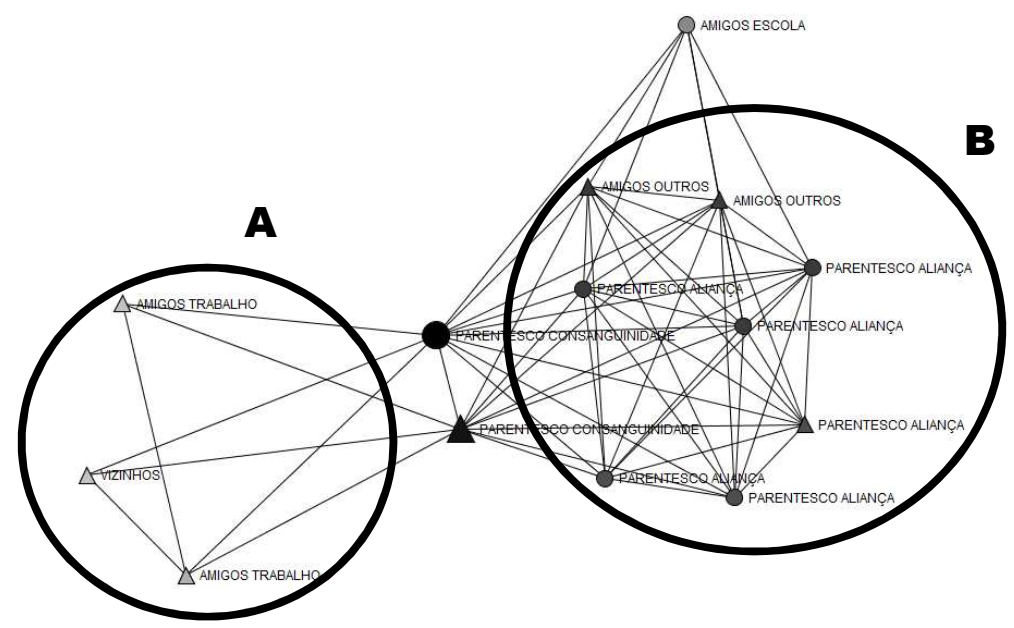

Fonte: Pesquisa Qualitativa. Elaboração própria.

Contudo, posteriormente e, principalmente após a migração, há visivelmente uma nova dinâmica de estabelecimento de contatos provedores de ajuda. O principal indício do impacto da migração na rede desses indivíduos é a não trivial presença e participação de vizinhos, de amigos do trabalho e de outros amigos; estes últimos muitas vezes vinculados a grupos específicos, por exemplo, associações de bairro, igrejas, mas principalmente, amigos de amigos. Assim, como ocorrido com Clara, o mesmo se deu com o Sr. Inocêncio (Diagrama 11, Diagrama 12 e Diagrama 13). 


\section{GRAFO Working Papers}

Número 1, diciembre 2012 No 01/03. ISSN: 2014-5993

Diagrama 11 - Rede de Suporte Social (Sr. Inocêncio) - Idoso, Migrante Intrametropolitano, Aposentado e Casado - 1a Migração - Responsável por Domicílio Urbano, Entrevistas Qualitativas, Região Metropolitana de Campinas, 2012

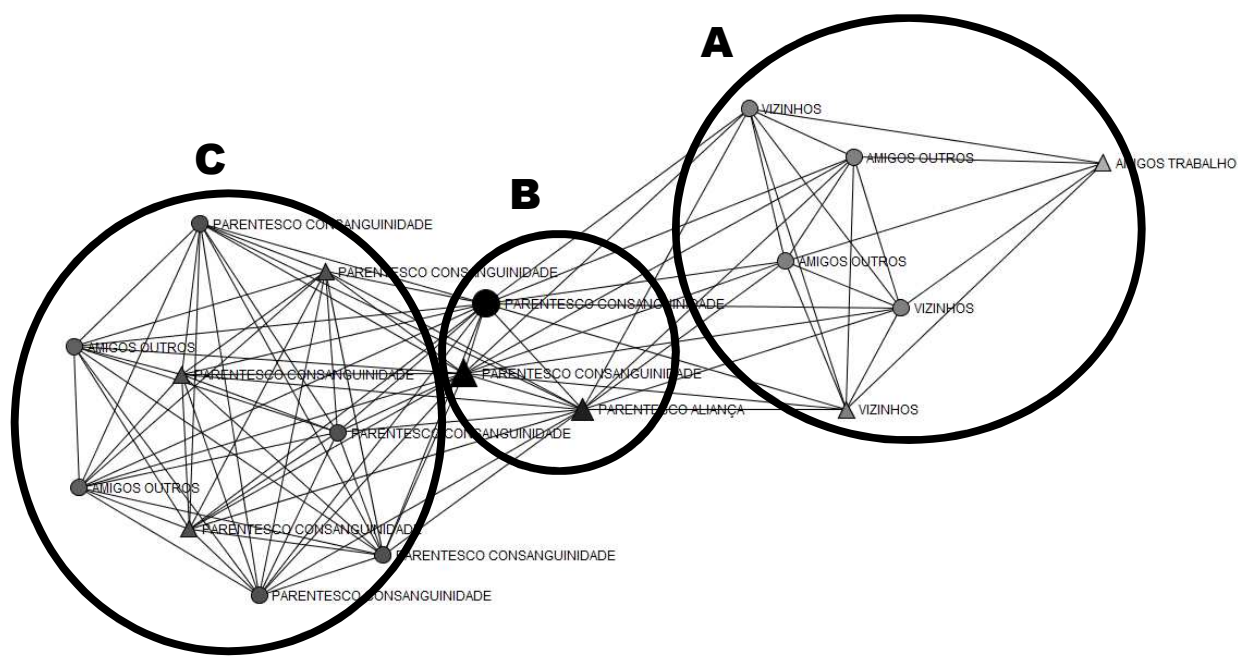

Fonte: Pesquisa Qualitativa. Elaboração própria.

Diagrama 12 - Rede de Suporte Social (Sr. Inocêncio) - Idoso, Migrante Intrametropolitano, Aposentado e Casado - 2a Migração - Responsável por Domicílio Urbano, Entrevistas Qualitativas, Região Metropolitana de Campinas, 2012

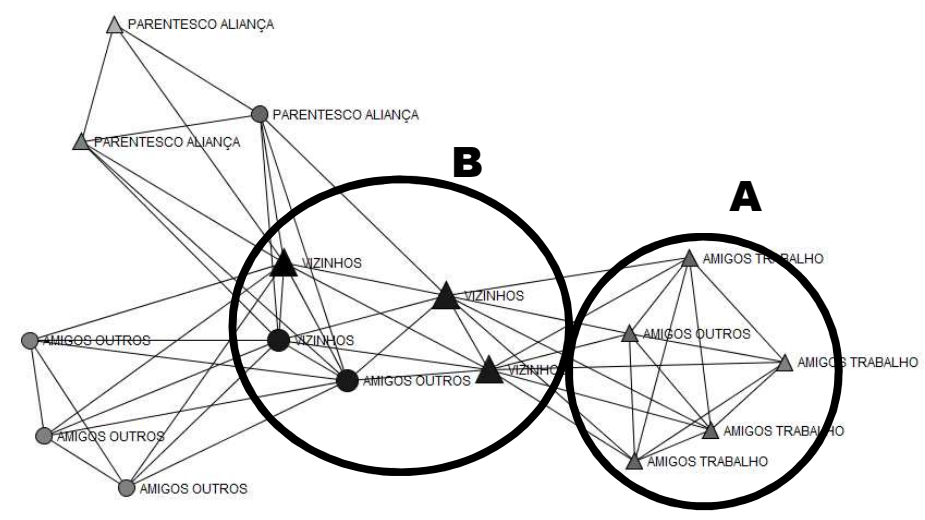

Fonte: Pesquisa Qualitativa. Elaboração própria. 


\section{GRAFO Working Papers}

Número 1, diciembre 2012 No 01/03. ISSN: 2014-5993

Diagrama 13 - Rede de Suporte Social (Sr. Inocêncio) - Idoso, Migrante Intrametropolitano, Aposentado e Casado - 3a Migração - Responsável por Domicílio Urbano, Entrevistas Qualitativas, Região Metropolitana de Campinas, 2012

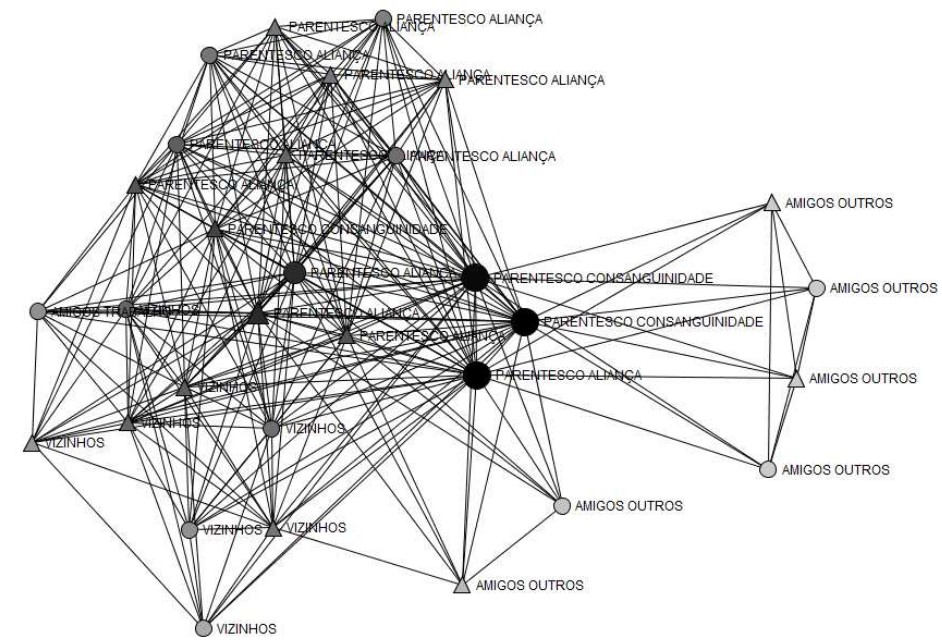

Fonte: Pesquisa Qualitativa. Elaboração própria.

O que se sucede muitas vezes é que há uma espécie de "enxugamento" da rede de suporte social dos mais idosos (migrantes ou não) para alguns tipos de recursos - essencialmente financeiros. Uma hipótese é que tal processo está associado ao próprio acúmulo de riquezas que um idoso teve ao longo da vida, situação totalmente distinta a de um jovem que possivelmente está ingressando agora no mercado de trabalho (Gráfico 1).

Gráfico 1 - Migrantes responsáveis por domicílios urbanos e seus cônjuges por tempo de residência, segundo possíveis fontes provedoras de ajuda financeira - primeira fonte. Região Metropolitana de Campinas, 2007

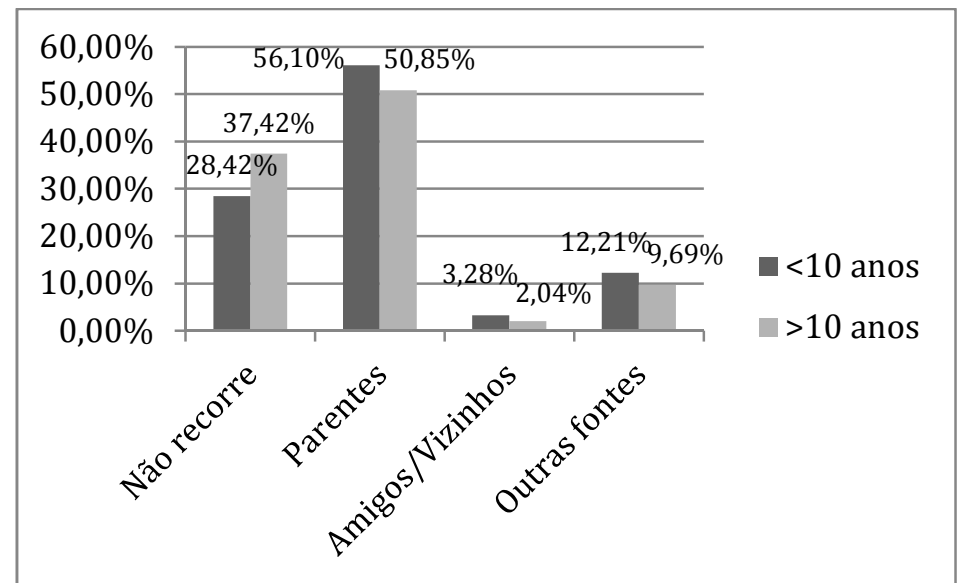

Fonte: Pesquisa Domiciliar do Projeto Vulnerabilidade (FAPESP/CNPq). NEPO/UNICAMP, 2007. 
Número 1, diciembre 2012 No 01/03. ISSN: 2014-5993

Os dados apresentados no Gráfico 1 são condizentes ao afirmado. Ou seja, boa parte dos migrantes com mais de 10 anos de residência na região não recorrem a ninguém. Enquanto que comparativamente os migrantes recentes se apoiam mais fortemente nos contatos familiares, mas também amigos, vizinhos e mesmo em outras fontes.

Os dados sugerem, portanto, que estágios iniciais de autonomia e independência destes chefes domiciliares - assim como fez a migração - força-os a buscar novas fontes de ajuda e suporte, ou seja, força a diversificação da rede. Contudo, com o passar do tempo boa parte desses mesmos contatos será "filtrada", haja vista que os indivíduos se encontram mais independente financeiramente e, logo, menos dependentes de sua rede de suporte social ao menos para esse específico recurso.

\section{Uma mão lava a outra}

Fica claro, a partir dos casos apresentados, que a migração provoca um processo de diversificação da rede de suporte social do migrante devido, essencialmente, a uma certa distância física estabelecida entre o entrevistado e seus antigos laços fortes (seus principais antigos provedores de ajuda e recursos - fossem eles parentes ou não).

No entanto, é bem verdade que justamente no período de transição e adaptação ao destino há uma espécie de hiato na rede de suporte social dos migrantes, uma vez que ele fica de certa forma alijado de parte de seus anteriores contatos sem que hajam novos para ocupar o posto dos antigos. Ou seja, ao menos nesse momento particular, a capacidade de resposta a riscos e adversidades por parte de migrantes e suas famílias é seriamente comprometida. Em outras palavras, migrantes estão mais propensos a se encontrar em uma condição/situação de vulnerabilidade social derivada de uma condição/situação (temporária, mas que pode perdurar mais ou menos) de vulnerabilidade relacional; pois parte de sua rede de suporte não consegue mais ser mobilizada da mesma forma que era anteriormente.

São, portanto, as famílias migrantes mais pobres aquelas cuja migração possivelmente conduziu a uma situação de vulnerabilidade social e relacional? Possivelmente sim, mas é importante frisar, talvez só no primeiro momento.

Isto porque parece que há um claro processo de geração de novos contatos logo após esse momento que foi descrito por boa parte dos migrantes como muito benéfico, sendo que ele não se restringiu somente a uma categoria de vinculação, mas foi salutar tanto para laços fortes como fracos (Gráfico 2). 


\section{GRAFO Working Papers}

Número 1, diciembre 2012 No 01/03. ISSN: 2014-5993

Gráfico 2 - Migrantes responsáveis por domicílios urbanos e seus cônjuges segundo possibilidade de contar com a ajuda de diversas fontes ao se mudar para o atual município de residência. Região Metropolitana de Campinas, 2007.

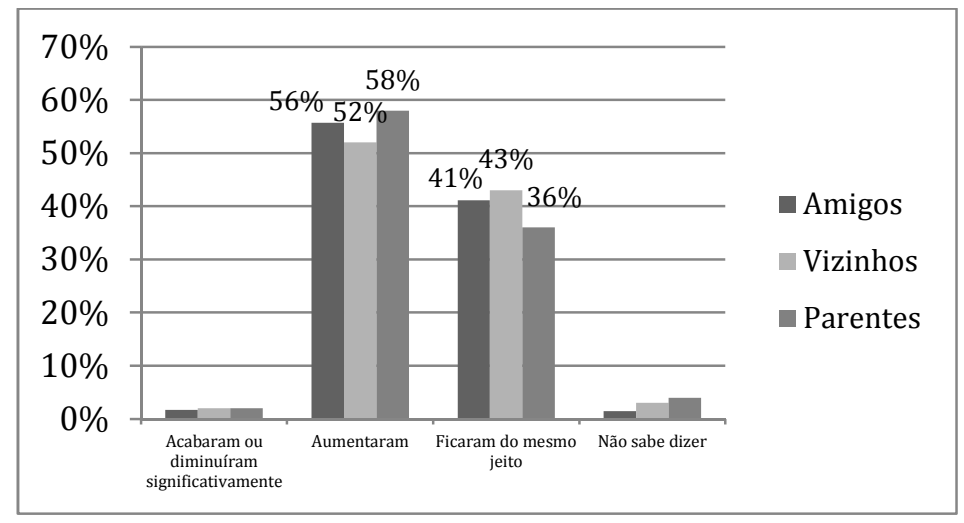

Fonte: Pesquisa Domiciliar do Projeto Vulnerabilidade (FAPESP/CNPq). NEPO/UNICAMP, 2007.

$\mathrm{E}$, de modo mais efetivo, são justamente os ditos migrantes mais pobres aqueles que, na maioria das vezes, se beneficiaram da migração (Tabela 1).

Tabela 1 - Migrantes responsáveis por domicílios urbanos e seus cônjuges segundo zonas de vulnerabilidade e possibilidade de contar com a ajuda de diversas fontes ao se mudar para o atual município de residência. Região Metropolitana de Campinas, 2007.

\begin{tabular}{|c|c|c|c|c|c|c|c|c|}
\hline \multicolumn{9}{|c|}{ Possibilidade de contar com a ajuda de: } \\
\hline ZV & Tendência & $\begin{array}{c}\text { Acabaram ou } \\
\text { diminuíram } \\
\text { significativamente }\end{array}$ & Tendência & Aumentaram & Tendência & $\begin{array}{c}\text { Ficaram } \\
\text { do } \\
\text { mesmo } \\
\text { jeito }\end{array}$ & Tendência & $\begin{array}{c}\text { Não sabe } \\
\text { dizer }\end{array}$ \\
\hline \multicolumn{9}{|c|}{ Amigos } \\
\hline 1 & $\bar{\nabla}$ & $3,40 \%$ & $\boldsymbol{\Delta}$ & $55,80 \%$ & - & $40,80 \%$ & - & $0,00 \%$ \\
\hline 3 & $\Delta$ & $4,70 \%$ & $\nabla$ & $47,30 \%$ & - & $45,20 \%$ & - & $2,80 \%$ \\
\hline \multicolumn{9}{|c|}{ Vizinhos } \\
\hline 1 & $\nabla$ & $3,40 \%$ & $\mathbf{\Delta}$ & $54,80 \%$ & - & $41,80 \%$ & - & $0,00 \%$ \\
\hline 3 & $\Delta$ & $3,90 \%$ & $\boldsymbol{\nabla}$ & $41,20 \%$ & - & $49,30 \%$ & - & $5,50 \%$ \\
\hline \multicolumn{9}{|c|}{ Parentes } \\
\hline 1 & $\nabla$ & $2,40 \%$ & $\mathbf{\Delta}$ & $58,50 \%$ & - & $36,80 \%$ & - & $2,30 \%$ \\
\hline 3 & $\Delta$ & $3,50 \%$ & $\nabla$ & $48,10 \%$ & - & $42,80 \%$ & - & $5,60 \%$ \\
\hline
\end{tabular}

Fonte: Pesquisa Domiciliar do Projeto Vulnerabilidade (FAPESP/CNPq). NEPO/UNICAMP, 2007.

Pois, posteriormente, são eles também os que mais incrementam suas redes de suporte e tiram vantagens desse incremento, posto que elas voltam a figurar como " $A$ " fonte de ajuda mais imediatamente acessível. 
Número 1, diciembre 2012 No 01/03. ISSN: 2014-5993

O interessante é notar que a migração foi especialmente "benéfica" - ou ao menos possibilitou o incremento da utilização de redes cada vez mais diversificadas - justamente tendo-se em vista os mais vulneráveis socialmente. Ou seja, de certo modo aumentou sua capacidade de mobilização de recursos.

Dessa forma, parece que os dados aqui apresentados vão na contra mão do que afirma Phan et al. (2012), onde "[...] neighborhood deprivation is found to exacerbate the exclusion of poorer individuals from informal helping; it also makes it harder for residents to reciprocate when they do participate in helping activities". Ou seja, a participação e interação social nestas áreas não foram severamente afetadas - ao menos em termos de privação como sugerido pela autora - por se viver nessas áreas, mas sim por talvez outros condicionantes macroestruturais relacionados a "geografia de oportunidades", ou melhor, ineficiência dela, como apontado por Kaztman (2001).

Enquanto que a maior disponibilidade de capital físico/financeiro daqueles que vivem em zonas menos vulneráveis garantiam outras formas enfrentamento as suas particulares adversidades.

Parece que esta não é uma saída ou opção possível para muitos dos mais vulneráveis que, portanto, se veem obrigados a recorrer a outras fontes, das quais as redes de suporte social cumprem um relevante papel.

\section{Considerações Finais}

A migração mesmo carregando alguns ônus iniciais - uma maior propensão a se encontrar em uma condição/situação de vulnerabilidade social derivada de uma condição/situação de vulnerabilidade relacional -, parece que foi responsável por um considerável incremento das fontes de ajuda, recursos e suportes. Assim, esses ditos ônus iniciais foram progressivamente transformados em bônus ao longo do tempo e do espaço. E, foram especialmente relevantes justamente para os mais vulneráveis socialmente.

Como dito anteriormente não é possível afirmar que essa diversificação da rede de suporte social do migrante assegure uma mobilidade social ascendente. Todavia, ela garantiu que para parcela significativa dos migrantes a ajuda prestada fosse essencial para suas reais necessidades, muitas delas imediatas. Ou seja, garantiram que novas fontes fossem incorporadas e mobilizadas em momentos de real e urgente necessidade - provavelmente diferentemente do que ocorria no destino e, logo, com consequências outras. 


\section{GRAFO Working Papers}

Número 1, diciembre 2012 No 01/03. ISSN: 2014-5993

Nesse sentido, há a uma desconstrução - ou no mínimo problematização - da lógica da exclusão, da marginalidade, da segregação, etc., onde o migrante era figura central.

Não negamos que isso de fato ocorra e persista, principalmente entre os migrantes mais pobres, mas parece, a partir dos dados apresentados, que esses processos sinistros não se devem, necessariamente a migração, visto que para muitos foi tida como uma solução benéfica em diversos sentidos, mas a mecanismos e lógicas de expropriação econômica e social persistentes em um país tão desigual quanto é o Brasil, deficiente em políticas públicas de equidade social realmente efetivas e capilarizadas. 
Número 1, diciembre 2012 No 01/03. ISSN: 2014-5993

\section{Agradecimentos}

Gostaria de agradecer muitíssimo ao Professor (e amigo) José Luis Molina pela ajuda e paciência prestadas na elaboração deste artigo. Paciência de professor em ensinar boa parte do que aqui foi apresentado.

\section{Bibliografia}

Avenarius, C. B. 2012. "Immigrant Networks in New Urban Spaces: Gender and Social Integration." International Migration.

Barrera, M., Jr. 1980. "A method for the assessment of social support netwoks in community survey research". Connections, v. 3(3), p. 8-13.

Bidart, Claire and Lavenu, Daniel. 2005. "Evolutions of Personal Networks and Life Events." Social Networks 27: 359-376.

Bonet i Marti, J. 2006. "La vulnerabilidad relacional: Análisis del fenómeno y pautas de intervención". Revista hispana para el análisis de redes sociales (Revista electrónica), v. 11, n. 4. Disponível em: <http://revista-redes.rediris.es>. Acessado: 20 de Janeiro de 2012.

Clark, William. A. V. and Huang, Youqin. 2003. "The Life Course and Residential Mobility in British Housingmarkets." Environment and Planning A 35: 323-339.

Cunha, J.M.P. (Org.). 2006. "Novas Metrópoles Paulistas: população, vulnerabilidade e segregação". Campinas: NEPO/UNICAMP.

; Jakob, A. A.; Cunha, T. A. 2009. "Dinâmica intra-urbana: migração e redes sociais na Região Metropolitana da Baixada Santista". Campinas: NEPO/UNICAMP.

DeAngelis, T. 1995. "A nation of hermits: The loss of community". APA Monitor, 26, 1, 46.

Hedman, Lina. 2012. "Moving Near Family? the Influence of Extended Family on Neighbourhood Choice in an Intra-Urban Context." Population, Space and Place.

Jariego, I. M.; Holgado, D. 2005. "Lazos fuertes y proveedores múltiples de apoyo: comparación de dos formas de representación gráfica de las redes personales". Empiria. Revista de metodología de ciencias sociales, 10, 107-127.

Kaztman, R. 2001. "Seducidos y abandonados: el aislamiento social de los pobres urbanos". Revista da CEPAL, Santiago de Chile, n.75. 


\section{GRAFO Working Papers}

Número 1, diciembre 2012 No 01/03. ISSN: 2014-5993

Lozares, C.; Molina, J. L. 2011. "Cohesión, Vinculación e Integración sociales en el marco del Capital Social". Revista hispana para el análisis de redes sociales (Revista electrónica), v. 4, n. 2. Disponível em: < http://revista-redes.rediris.es>. Acessado: 05 de Janeiro de 2011.

Magdol, Lynn and Bessel, Diane R.. 2003. "Social Capital, Social Currency, and Portable Assets: The Impact of Residential Mobility on Exchanges of Social Support." Personal Relationships 10: 149-169.

Molina, J.L.; Jürgen, L.; Mestres, S.G. 2008. "Patrones de cambio de las redes personales de inmigrantes en Cataluña". Revista hispana para el análisis de redes sociales (Revista electrónica), v. $15, \quad$ n. 4. Disponível em: $<$ http://revista-redes.rediris.es $/ \mathrm{html}$ vol15/Vol15 4.htm>. Acessado: 05 de Outubro de 2012.

Phan, Mai. B., Blumer, N., and Demaiter, Erin I. 2009. "Helping Hands: Neighborhood Diversity, Deprivation, and Reciprocity of Support in Non-Kin Networks." Journal of Social and Personal Relationships 26 (6-7): 899-918.

Singer, P. 1980. "Migrações Internas: Considerações Teóricas Sobre o Seu Estudo." In: MOURA, H. (Org.). Migração interna: textos selecionados. Fortaleza: Banco do Nordeste do Brasil S.A.

Viry, Gil. 2012. "Residential Mobility and the Spatial Dispersion of Personal Networks: Effects on Social Support." Social Networks 34 (1): 59-72. 